\title{
Optimal operation of tubular reactors for naphtha cracking by
} numerical simulation

\author{
G.-Y. Gao ${ }^{\text {a }}$ M. Wang ${ }^{\text {b* }}$, C. Ramshaw ${ }^{\text {b }}$ X.-G. Li ${ }^{\mathrm{a}}$, H. Yeung ${ }^{\mathrm{b}}$ \\ ${ }^{a}$ School of Chemical Engineering and Technology, TianJin University, 300072, P.R.China \\ ${ }^{b}$ Process Systems Engineering Group, School of Engineering, Cranfield University, MK43 OAL, UK
}

\begin{abstract}
Process gas temperature profile and steam to hydrocarbon ratio in the feed have important impact on product yields and coking rate in tubular reactors for naphtha cracking. This study is to evaluate these effects quantitatively based on numerical simulation. Steady-state operation of the tubular reactor in an industrial thermal cracking furnace presented was first simulated in HYSYS with a molecular reaction scheme. Various case studies then investigate the influence of process gas temperature profile and inlet steam to hydrocarbon ratio so that the ethylene/propylene product yields and coking rate can be evaluated. Finally, steady-state optimisation was applied to the operation of this industrial furnace. The optimal process temperature profile and the optimal inlet steam to naphtha ratio were found to maximize the operation profit. This study will provide significant guidance to process engineers in the ethylene industry.
\end{abstract}

Keywords: ethylene furnace, thermal cracking reaction, tubular reactor, process simulation, optimal operation

\section{INTRODUCTION}

Ethylene is the one of most important building blocks used in the petrochemical industry. Thermal cracking of hydrocarbons is the main route for the manufacturing of ethylene and propylene [1]. Although ethane, propane, butane, naphtha and gas oil can be used as feedstocks for cracking reactions, naphtha is the most frequently used raw material [2]. Therefore, naphtha cracking is the focus of this study.

\subsection{Thermal cracking furnace}

The thermal cracking furnace is the heart of the whole ethylene manufacturing process. A typical unit generally includes the convection section, the cross-over section and the radiation section [1,2]. Naphtha is preheated in the convection section and then mixed with steam. The mixture of naphtha and steam is introduced into the tubular reactors or cracking coils in the radiation section at a high temperature. The cracking reactions take place inside these long tubular reactors. Firebox and burners were designed to apply a high heat flux to the outer reactor tube surface so that the process gases reach their reaction temperature rapidly. Steam is a diluent and it is used to improve olefin selectivity and reduce coking rate.

\subsection{Literature review}

This section is a summary of the current developments in the reaction schemes for naphtha cracking, modelling, simulation and optimisation study of tubular reactors. 
The naphtha cracking process involves many free-radical reactions. Towfighi and Karimzadeh published a free-radical reaction scheme for naphtha cracking which includes 150 reactions [3]. Due to computation difficulties, models based on molecular reactions have been widely used [2]. Wang et al. developed a molecular reaction mechanism for steam cracking of naphtha [4, 5]. Kumar and Kunzru proposed another molecular reaction mechanism for naphtha steam cracking based on their laboratory experimentation [6]. In the meantime, Kumar and Kunzru developed a kinetics model for predicting coking rate [7].

Shahrokhi and Nejati carried out an optimal operation study based on 1-dimensional (1D) plug flow steady-state model for propane thermal cracking [8]. Operating profit was used as objective function and the optimal temperature profile was obtained. In formulating the above objective function, the time required for decoking was considered and the cost for decoking operations were expressed as a fraction of the production revenue. Masoumi et al. developed a 1D steady-state model for tubular reactors in naphtha cracking [9]. A free-radical reaction scheme including 90 species and 543 reactions was used. An optimisation study was performed with the aim to maximize operating profit. In the study, the optimal coil outlet temperature was found to be $1150.49 \mathrm{~K}$. At this condition, the ethylene yield was $33.74 \%$ and the coking rate was around $0.008 \mathrm{~g} / \mathrm{cm}^{2} \min$.

In a thermal cracking furnace, complex transfers (such as mass, momentum and heat transfers), thermal cracking reactions and fuel combustion take place. These are closely coupled and interacted with each other. Previous studies focused on the simulation of thermal cracking reactions and radiative heat transfer while the flows of process gas and flue gas were simplified [2]. The plug-flow assumption of process gas and flue gas results in significant differences in simulation results compared to simulations with a realistic flow field [10]. The difference between the temperature at the tube centre and the temperature at the tube wall has a significant effect on the reaction in a thermal cracking furnace. Thus, 3-dimensional (3D) Computational Fluid Dynamics (CFD) simulations were used in [10, 11].

\subsection{The motivation and aim of this study}

By comparison, the 1D steady-state models (especially with commercial tools such as HYSYS and Aspen Plus) are easy and fast to develop. The 1D simulation could provide reasonably accurate results. On the contrary, 3D CFD models would require many technical details for configuration. It also requires lots of computation. Generally, the results from 3D CFD simulation could be more accurate. Therefore, there is a tradeoff between efforts, computation and accuracy of simulation results.

This paper concentrates on tubular reactors and the cracking reactions inside them. So far, no publications can be found in the literature to quantitatively evaluate the impact of process gas temperature profile and steam to hydrocarbon ratio in the feed on the ethylene/propylene product yields and coking rate based on a real industrial thermal cracking furnace.

The study is based on steady-state simulation and optimisation using HYSYS [12]. Tubular reactors of a real industrial thermal cracking furnace presented in [10] were simulated with the molecular reaction scheme proposed in [6]. The reaction scheme published in [4, 5] was originally used by Lan et al. [10]. It was not used in this study since insufficient detail was given. The impact of process gas temperature profile and inlet steam to hydrocarbon ratio on the ethylene/propylene product yields and coking rate 
were evaluated by varying the operating conditions of the tubular reactors. In the study for optimal operation, operation profit was used as objective function. The process gas temperature profile and inlet steam to hydrocarbon ratio were used as optimisation variables. The effect of coking on reduction of manufacturing time and the decoking cost have been considered.

The present work is different from those published in the literature in three main respects: (a) all the case studies were performed based on the same real industrial naphtha cracking furnace; (b) The tubular reactor operation optimisation has been studied systematically; (c) the simulation and optimisation tool HYSYS is commercially available and easy to use. These features should make this study very appropriate to practising process engineers in the ethylene industry.

The paper is laid out as follows. Details of the base case simulation will be described in Section 2. Various case studies will be conducted in Section 3. Section 4 is to study the optimal operation. Conclusions will be drawn in the end.

\section{SIMULATION of A BASE CASE}

\subsection{Tubular reactors and operating conditions}

The simulation is based on long tubular reactors of a real industrial thermal cracking furnace described in [10]. The whole furnace has 40 identical reaction tubes. Each tubular reactor is constructed by 2 passes of different diameters. The reactor feed contains naphtha and dilution steam. The feed has a mass flowrate $11,500 \mathrm{~kg} / \mathrm{h}$ for naphtha and a mass flowrate of $6,900 \mathrm{~kg} / \mathrm{h}$ for steam. In this way, the mixture of naphtha and steam has a mole flow rate of $509 \mathrm{kmol} / \mathrm{h}$ and steam to naphtha ratio in the feed is 0.6 to 1 . Feed temperature is $853 \mathrm{~K}$ and pressure is $206 \mathrm{kPa}$. Outlet temperature is controlled at 1,068 K and pressure at $172 \mathrm{kPa}$.

\subsection{Reaction scheme}

The molecular reaction scheme proposed by Kumar and Kunzru [6] was adopted since it has been widely cited. This reaction scheme contains 1 primary reaction (first order) and 21 secondary reactions (first order). Due to different naphtha as feedstock, the stoichiometric coefficients for primary reaction were adjusted according to the naphtha properties used in [10]. Among the 21 secondary reactions, numbers 2, 3, 7 and 16 are reversible reactions. But the kinetics data for these 4 reverse reactions were not given in [6]. Therefore, the reaction equilibrium constants for these 4 reverse reactions were extracted from [13]. Reverse reaction kinetic parameters were then calculated with $k_{R}=k_{F} / k_{C}$, where $k_{R}$ denotes reverse reaction rate constant, $\mathrm{k}_{\mathrm{F}}$ the forward react rate constant and $\mathrm{k}_{\mathrm{C}}$ the reaction equilibrium constant. The final reaction mechanism used is listed in Table 1 and Table 2.

Table 1 Reaction scheme for naphtha cracking used in this study

\begin{tabular}{llcc}
\hline No. & \multicolumn{1}{c}{ Reaction equations } & $\mathrm{K}_{0}, \mathrm{~s}^{-1}$ & $\mathrm{E}, \mathrm{cal} / \mathrm{mol}$ \\
\hline 1 & $\mathrm{C}_{6.5} \mathrm{H}_{14}=>0.50 \mathrm{H}_{2}+0.76 \mathrm{CH}_{4}+1.16 \mathrm{C}_{2} \mathrm{H}_{4}+0.13 \mathrm{C}_{2} \mathrm{H}_{6}+0.38 \mathrm{C}_{3} \mathrm{H}_{6}$ & $6.565 \mathrm{E}+11$ & 52,580 \\
& $+0.09 \mathrm{C}_{3} \mathrm{H}_{8}+0.008 \mathrm{C}_{4} \mathrm{H}_{10}+0.245 \mathrm{C}_{4} \mathrm{H}_{8}+0.113 \mathrm{C}_{4} \mathrm{H}_{6}+0.08 \mathrm{C}_{4}{ }^{\prime} \mathrm{s}$ & & \\
2 & $\mathrm{C}_{2} \mathrm{H}_{6} \Leftrightarrow=\mathrm{C}_{2} \mathrm{H}_{4}+\mathrm{H}_{2}$ & $4.652 \mathrm{E}+13$ & 65,210 \\
3 & $\mathrm{C}_{3} \mathrm{H}_{6} \Leftrightarrow=\mathrm{C}_{2} \mathrm{H}_{2}+\mathrm{CH}_{4}$ & $7.284 \mathrm{E}+12$ & 65,330 \\
4 & $\mathrm{C}_{2} \mathrm{H}_{2}+\mathrm{C}_{2} \mathrm{H}_{4}=>\mathrm{C}_{4} \mathrm{H}_{6}$ & $(1.026 \mathrm{E}+15)^{\mathrm{b}}$ & 41,260 \\
\hline
\end{tabular}




\begin{tabular}{llcc}
\hline 5 & $2 \mathrm{C}_{2} \mathrm{H}_{6}=>\mathrm{C}_{3} \mathrm{H}_{8}+\mathrm{CH}_{4}$ & $3.75 \mathrm{E}+12$ & 65,250 \\
6 & $\mathrm{C}_{2} \mathrm{H}_{4}+\mathrm{C}_{2} \mathrm{H}_{6}=>\mathrm{C}_{3} \mathrm{H}_{6}+\mathrm{CH}_{4}$ & $(7.083 \mathrm{E}+16)^{\mathrm{b}}$ & 60,430 \\
7 & $\mathrm{C}_{3} \mathrm{H}_{8} \Leftrightarrow>\mathrm{C}_{3} \mathrm{H}_{6}+\mathrm{H}_{2}$ & $5.888 \mathrm{E}+10$ & 51,290 \\
8 & $\mathrm{C}_{3} \mathrm{H}_{8}=>\mathrm{C}_{2} \mathrm{H}_{4}+\mathrm{CH}_{4}$ & $4.692 \mathrm{E}+10$ & 50,600 \\
9 & $\mathrm{C}_{3} \mathrm{H}_{8}+\mathrm{C}_{2} \mathrm{H}_{4}=>\mathrm{C}_{2} \mathrm{H}_{6}+\mathrm{C}_{3} \mathrm{H}_{6}$ & $(2.536 \mathrm{E}+16)^{\mathrm{b}}$ & 59,060 \\
10 & $2 \mathrm{C}_{3} \mathrm{H}_{6}=>3 \mathrm{C}_{2} \mathrm{H}_{4}$ & $7.386 \mathrm{E}+12$ & 64,170 \\
11 & $2 \mathrm{C}_{3} \mathrm{H}_{6}=>0.3 \mathrm{C}_{\mathrm{n}} \mathrm{H}_{2 \mathrm{n}-6}+0.14 \mathrm{C}_{6}{ }^{+}+3 \mathrm{CH}_{4}$ & $2.424 \mathrm{E}+11$ & 56,900 \\
12 & $\mathrm{C}_{3} \mathrm{H}_{6}+\mathrm{C}_{2} \mathrm{H}_{6}=>\mathrm{C}_{4} \mathrm{H}_{8}+\mathrm{CH}_{4}$ & $(1.000 \mathrm{E}+17)^{\mathrm{b}}$ & 60,010 \\
13 & $\mathrm{C}_{4} \mathrm{H}_{10}=>\mathrm{C}_{3} \mathrm{H}_{6}+\mathrm{CH}_{4}$ & $7.000 \mathrm{E}+12$ & 59,640 \\
14 & $\mathrm{C}_{4} \mathrm{H}_{10}=>2 \mathrm{C}_{2} \mathrm{H}_{4}+\mathrm{H}_{2}$ & $7.000 \mathrm{E}+14$ & 70,680 \\
15 & $\mathrm{C}_{4} \mathrm{H}_{10}=>\mathrm{C}_{2} \mathrm{H}_{4}+\mathrm{C}_{2} \mathrm{H}_{6}$ & $4.099 \mathrm{E}+12$ & 61,310 \\
16 & $\mathrm{C}_{4} \mathrm{H}_{10}<=>\mathrm{C}_{4} \mathrm{H}_{8}+\mathrm{H}_{2}$ & $1.637 \mathrm{E}+12$ & 62,360 \\
17 & $\mathrm{C}_{4} \mathrm{H}_{8}=>0.41 \mathrm{C}_{\mathrm{n}} \mathrm{H}_{2 \mathrm{n}-6}+0.19 \mathrm{C}_{6}{ }^{+}$ & $2.075 \mathrm{E}+11$ & 50,730 \\
18 & $\mathrm{C}_{4} \mathrm{H}_{8}=>\mathrm{H}_{2}+\mathrm{C}_{4} \mathrm{H}_{6}$ & $1.000 \mathrm{E}+10$ & 50,000 \\
19 & $\mathrm{C}_{2} \mathrm{H}_{4}+\mathrm{C}_{4} \mathrm{H}_{6}=>\mathrm{B}+2 \mathrm{H}_{2}$ & $(8.385 \mathrm{E}+12)^{\mathrm{b}}$ & 34,560 \\
20 & $\mathrm{C}_{4} \mathrm{H}_{6}+\mathrm{C}_{3} \mathrm{H}_{6}=>\mathrm{T}+2 \mathrm{H}_{2}$ & $(9.740 \mathrm{E}+11)^{\mathrm{b}}$ & 35,640 \\
21 & $\mathrm{C}_{4} \mathrm{H}_{6}+\mathrm{C}_{4} \mathrm{H}_{8}=>\mathrm{EB}+2 \mathrm{H}_{2}$ & $(6.400 \mathrm{E}+17)^{\mathrm{b}}$ & 57,970 \\
22 & $\mathrm{C}_{4} \mathrm{H}_{6}+\mathrm{C}_{4} \mathrm{H}_{6}=>\mathrm{ST}+2 \mathrm{H}_{2}$ & $(1.510 \mathrm{E}+12)^{\mathrm{b}}$ & 29,760 \\
\hline
\end{tabular}

B: benzene; T: toluene; EB: ethylbenzene; ST: styrene. ${ }^{\mathrm{b}}$ Units: $\mathrm{cm}^{3} /(\mathrm{mol} \mathrm{s})$.

Table 2 Reverse react rate constants for Kumar model (E, $\mathrm{kcal} / \mathrm{mol})$

\begin{tabular}{cc}
\hline No. & Reverse reaction rate constant $\left(1 \mathrm{~mol}^{-1} \mathrm{~s}^{-1}\right)$ \\
\hline Reaction 2 & $k_{R}=8.49 \times 10^{8} \exp \left(-\frac{32.63}{R T}\right)$ \\
Reaction 3 & $k_{R}=3.81 \times 10^{8} \exp \left(-\frac{35.17}{R T}\right)$ \\
Reaction 7 & $k_{R}=9.03 \times 10^{5} \exp \left(-\frac{22.34}{R T}\right)$ \\
Reaction 16 & $k_{R}=1.78 \times 10^{7} \exp \left(-\frac{32.3}{R T}\right)$ \\
\hline
\end{tabular}

\subsection{Base case simulation and results}

A 1D plug flow reactor (PFR) model was chosen in HYSYS to simulate the tubular reactors. The modified molecular reaction scheme was described above in section 2.2. The PFR sizes and operating conditions were described in section 2.1. Figure 1 shows the process gas temperature profile along the reactor tubes, which is the same as in [10]. This is the temperature profile used in real industry. 


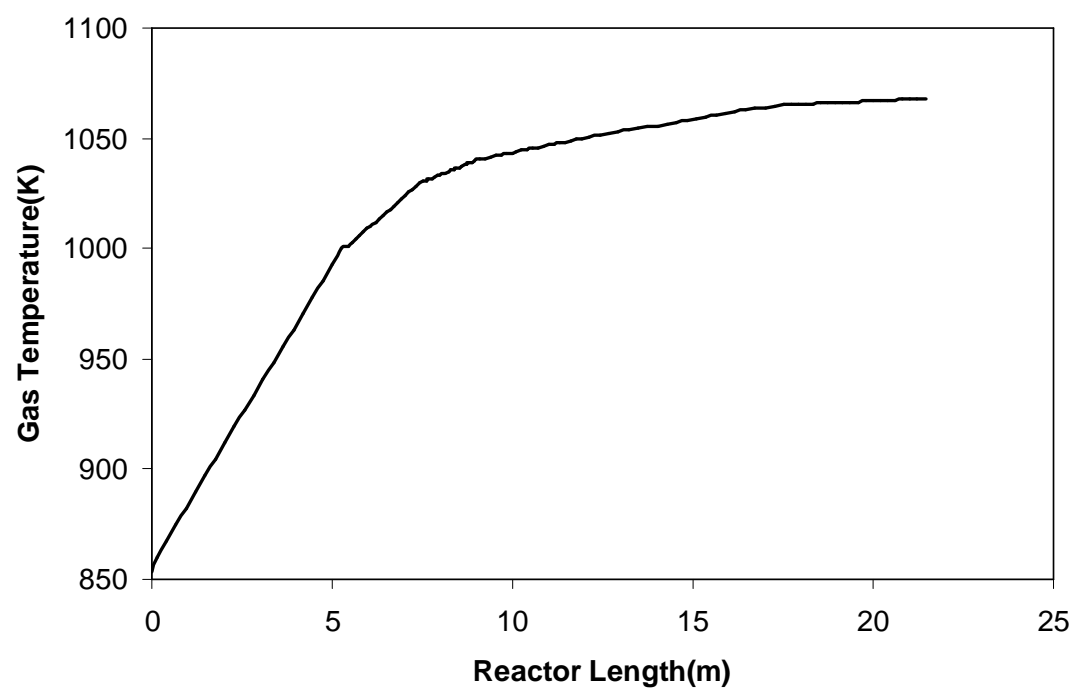

Figure 1 process gas temperature profile along the reactor tube

In Table 3, the main product yields from the base case simulation in HYSYS were compared with the corresponding industrial data from [10]. As can be seen, simulation yields are in good agreement with industrial values. This indicates that HYSYS simulation is a good reflection of the real process.

Table 3 Simulation results compared with industrial data

\begin{tabular}{ccc}
\hline Main products & yield (wt $\%)$ from HYSYS simulation & Industrial yield $(\mathrm{wt} \%)$ \\
\hline $\mathrm{H}_{2}$ & 0.86 & 0.72 \\
$\mathrm{CH}_{4}$ & 9.70 & 9.69 \\
$\mathrm{C}_{2} \mathrm{H}_{4}$ & 25.31 & 25.34 \\
$\mathrm{C}_{2} \mathrm{H}_{6}$ & 2.59 & 2.57 \\
$\mathrm{C}_{3} \mathrm{H}_{6}$ & 11.46 & 11.66 \\
$\mathrm{C}_{4} \mathrm{H}_{6}$ & 4.34 & 4.39 \\
\hline
\end{tabular}

Figure 2 shows the progress of the cracking reactions along the reactor tube. From Figures 1 and 2, it can be seen that process gas temperature increases rapidly along the first pass, but product yields go up slowly. Whilst in the second pass, process gas temperature increases gradually, main product yields increase sharply. This is because the naphtha cracking reactions are endothermic. The heat transferred through the tube wall is used to increase the process gas temperature and to provide the reaction heat. The reaction rate is accelerated with the increase of temperature. In the first pass, process gas temperature increases from 853 to $1050 \mathrm{~K}$, the reaction rate is still relatively slow. In the second pass, process gas temperature increases from 1050 to $1068 \mathrm{~K}$, the reaction rate becomes much faster. Clearly, most of the reaction is performed in the second pass where the gas temperatures are higher. The aromatics concentration which is a critical determinant for coke deposition [7] also increases in the second tube pass due to the secondary reactions occurring there. 


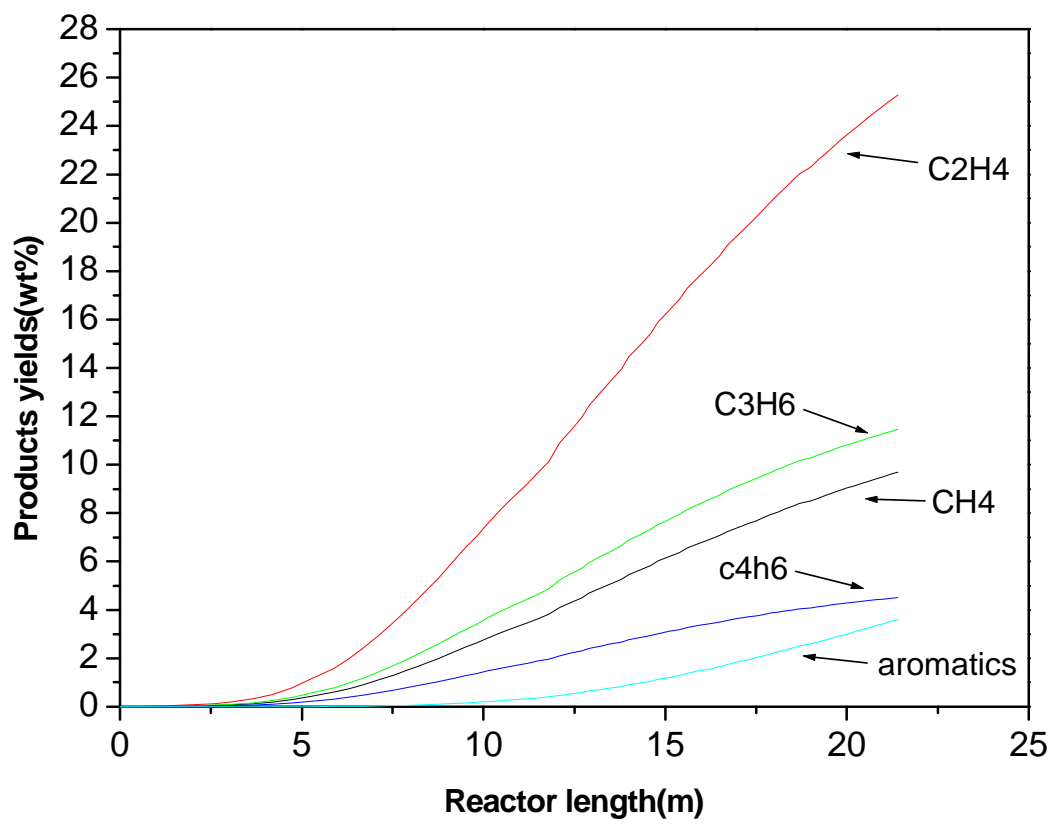

Figure 2 Main cracking product yields along the reactor tube

\section{CASE STUDIES}

\subsection{Effects of process gas temperature profile}

From the base case simulation in Section 2, the process gas temperature profile has an important effect on the cracking product yields. To further investigate this effect quantitatively, the following different cases were studied. Under the same feed conditions (i. e. the same naphtha was used and the steam to naphtha ratio is fixed at 0.6:1), only the process gas temperature profiles applied along the reactors were changed, the rest of the operating conditions are the same as in the base case. The process gas temperature profiles were produced in the following way: the initial temperature remained the same, the growth in temperature along the tube reactor were paralleled to the initial profile plus an increment proportional to the difference between the final outlet temperature and the distance along the tube reactor length. Different coil outlet temperatures (COT) were achieved (as shown in Figure 3). The first part of the temperature profile could not be steeper due to practical design limitations. 
Figure 3 Different process gas temperature profiles along the reactor tube

The simulation results on yields were summarized in Figure 4. Although the ethylene yield improved throughout the temperature range, there is a disappointing loss of propylene (an equally valuable product) beyond an exit temperature of $1,103.15 \mathrm{~K}$. In addition, the aromatics increased continuously throughout the temperature range. The aromatics is believed to be the main reason that causes coke deposition [7].

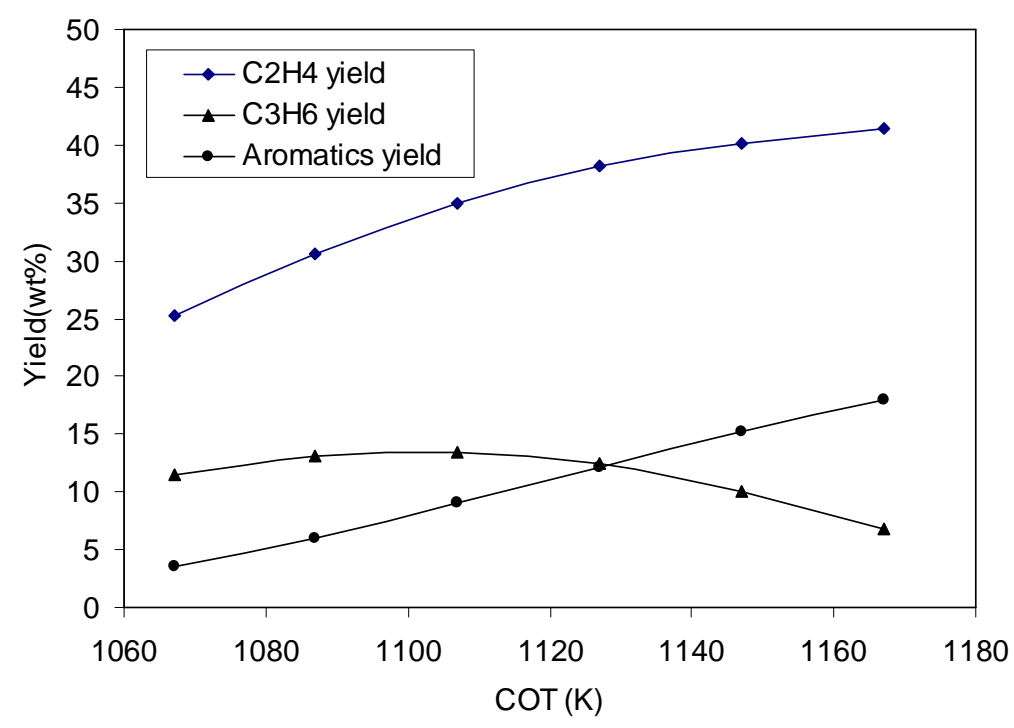

Figure 4 Effect of COT on product yields

Coking rate prediction proposed by Kumar and Kunzru [7] can be described as follows:

$$
R_{c}=1.95 * 10^{15} * \operatorname{EXP}(-212,260 / R T) * C_{\text {arom }}^{1.97}
$$

where $R_{c}$ denotes the coking rate in $\mathrm{kg} /\left(\mathrm{m}^{2} \mathrm{~h}\right)$ and $C_{\text {arom }}$ denotes the total aromatics concentration $\left(\mathrm{kmol} / \mathrm{m}^{3}\right)$. From equation (1), the coking rate should increase with process gas temperature accordingly. 
In the whole tubular reactor, the reactor outlet should have the highest temperature. Thus, it is important to check the coking behaviour at the tube outlet. Figure 5 shows the effect of the process gas temperature on coking rate at the tube outlet. With the COT increases, the coking rate increases dramatically. At higher coking rate, the coking will build up faster at the inner wall of the tube. The interval between decoking will be shorter. Generally a reactor decoking operation requires the unit to be taken off-line for $24-48$ hours, this interruption can have a significant negative impact on the overall production rate.

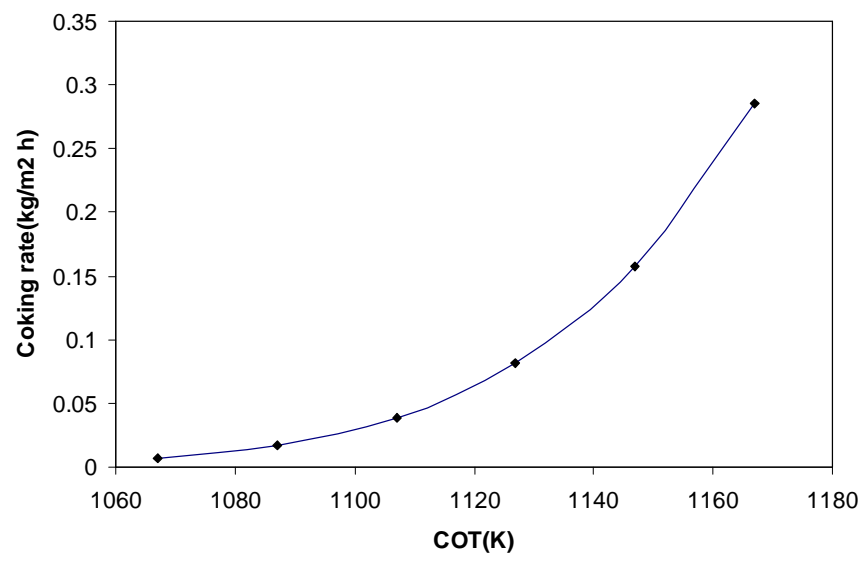

Figure 5 Effect of COT on coking rate

\subsection{Effects of steam to naphtha ratio in the feed}

To study the effects of steam to naphtha ratio in the feed on the product yields and the coking rate, different cases were designed. Same as in the base case, the feed has a fixed mole flow rate $509 \mathrm{kmol} / \mathrm{h}$ for naphtha and steam. Steam to naphtha ratio $(\mathrm{kg} / \mathrm{kg})$ varies between $0.2: 1$ and 1.3:1. The temperature profile applied along the tubular reactor is the same as in Figure 1. Figure 6 shows the trend of product yields changing with the steam to naphtha $(\mathrm{kg} / \mathrm{kg})$ ratio in the feed. As can be seen, there is little incentive from a yield point of view to increase the steam fraction beyond about 0.8 . However, it will be recognised that with a constant molar flow of reactants the ethylene/propylene production rates fall significantly at the higher steam dilutions. It is, therefore, imperative to operate at the lowest steam dilutions possible, provided that the resulting coking rate can be accepted.

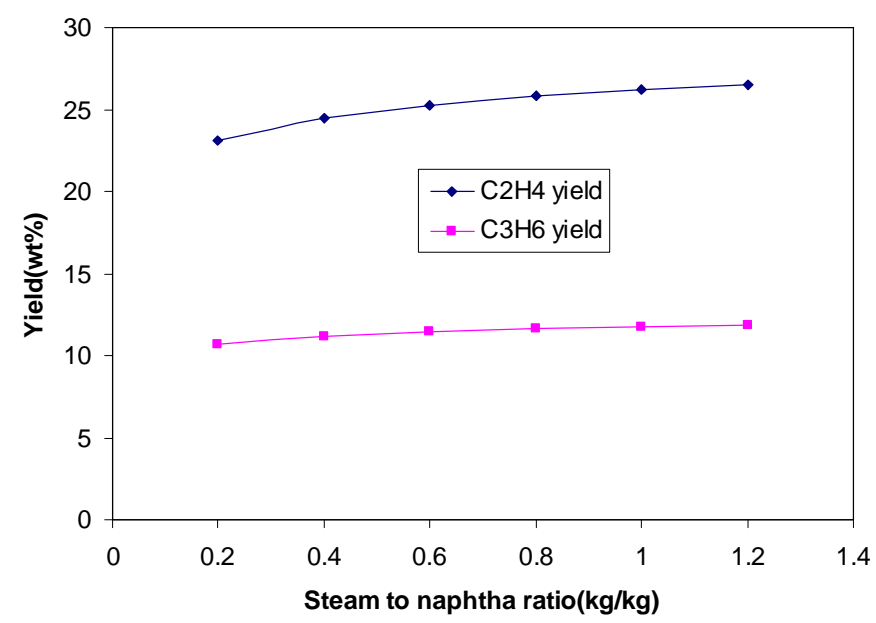

Figure 6 Effect of steam/naphtha $(\mathrm{kg} / \mathrm{kg})$ ratio in the feed on product yields 
With the model proposed by Kumar and Kunzru [7] to calculate the coking rate, the influence of steam dilution on the coking rate is represented in Figure 7 which shows a reduction from 0.0087 to 0.0063 $\mathrm{kg} /\left(\mathrm{m}^{2} \mathrm{~h}\right)$ as the steam ratio $(\mathrm{kg} / \mathrm{kg})$ increases from $0.2: 1$ to $1.3: 1$. On this basis, the choice of the 0.6 steam ratio used in the base case simulation appears to be a reasonable compromise. This trend can be explained theoretically. The increase of steam to naphtha ratio in the feed means the reduction of naphtha partial pressure in the feed.

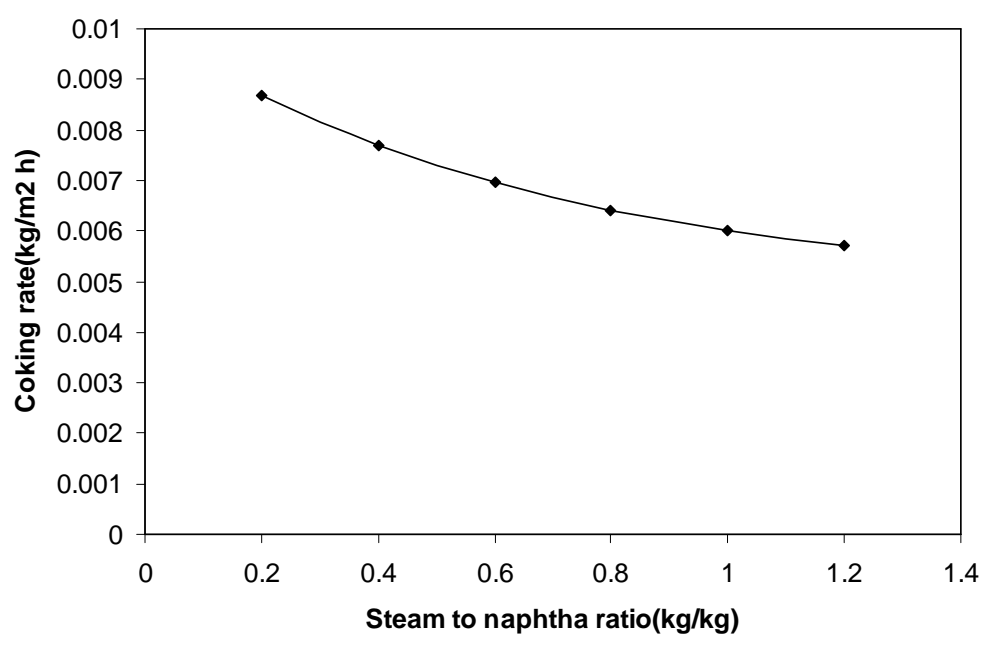

Figure 7 Effect of steam/naphtha ratio $(\mathrm{kg} / \mathrm{kg})$ on coking rate

\section{OPTIMAL OPERATION}

The most profitable operating conditions will be a complex balance involving the product yield, steam dilution, temperature profile and the coking rate (which results in appreciable "downtime"). The simulation results presented in Section 3 above suggest that the most sensitive operating parameter is likely to be the imposed reactant temperature profile followed by the steam to hydrocarbon ratio. These variables are, therefore, the focus of the optimisation work.

\subsection{Mathematical formulation of the optimal operation problem}

The following assumptions have been made for formulating this optimisation problem: (1) No downstream product separation costs are counted; (2) The impact of change in coking buildup (thickness) on heat transfer coefficient (through the pipe) is not considered.

In this study, the operating profit was used as the objective function. It was defined as the income from desired products minus various costs. Costs include raw material cost (naphtha here), cost for steam, cost for radiant heat plus decoking cost. A fixed value (denoted by DCC) was used for decoking cost. The operating profit was calculated on a yearly basis.

$$
\begin{aligned}
& f_{p}=\text { Income }- \text { Cost } \\
& \text { Income }=\left(t_{p}-n_{d} t_{d}\right) * \sum F_{i} c_{i} \\
& \text { Cost }=\left(t_{p}-n_{d} t_{d}\right) *\left(F_{0} c_{0}+F_{H} c_{H}+Q c_{Q}\right)+n_{d} * D C C
\end{aligned}
$$


Where $f_{p}$ represents the operating profit, $F_{i}$ the desirable product flow rate, $F_{0}$ the naphtha flow rate; $F_{H}$ the steam flow rate; $n_{d}$ denotes the decoking times per year. The meaning for other parameters can be referred to Table 4.

The decoking frequency is calculated via Equations (5) and (6).

$$
\begin{aligned}
& n_{d}=\frac{t_{p}}{t_{d}+t_{e}} \\
& t_{e}=\frac{\delta_{c} d_{c}}{R_{c}}
\end{aligned}
$$

Where $t_{e}$ denotes the production time between consecutive decoking processes (unit in hours); $\delta_{c}$ denotes allowed coke thickness (before decoking) in $\mathrm{m} ; d_{c}$ denotes the coke density $\left(\mathrm{kg} / \mathrm{m}^{3}\right) ; R_{c}$ denotes the coking rate in $\mathrm{kg} /\left(\mathrm{m}^{2} \mathrm{~h}\right)$.

In summary, the optimal operation study wants to maximize the operation profit when the process gas temperature profile along the reactor and the steam to naphtha ratio in the feed vary within certain ranges. Mathematically it was described as following:

$$
\begin{gathered}
\max \left(t_{p}-n_{d} t_{d}\right) * \sum F_{i} c_{i}-\left(t_{p}-n_{d} t_{d}\right) *\left(F_{0} c_{0}+F_{H} c_{H}+Q c_{Q}\right)-n_{d} * D C C \\
\text { s.t. }\left\{\begin{array}{l}
853 \mathrm{~K} \leq T_{o} \leq 1153 \mathrm{~K} \\
0.3 \leq \text { steam / naphtha }(\mathrm{kg} / \mathrm{kg}) \leq 0.9
\end{array}\right.
\end{gathered}
$$

\subsection{Case study}

The yearly production time $\left(t_{p}\right)$ is assumed to be 340 days and 24 hours per day. Table 4 gave other parameters assumed for this case study. The price factors for ethylene, propylene and naphtha were taken from [14].

Table 4 Parameters for optimal operation case study

\begin{tabular}{|c|c|c|}
\hline Physical meaning & Parameters & Values \\
\hline The yearly production time & $t_{p}$, hour & 8160 \\
\hline decoking time per period/cycle & $t_{d}$, hour & 48 \\
\hline The allowed coke thickness & $\delta_{c}, \mathrm{~m}$ & 0.006 \\
\hline the coke density & $d_{c}, \mathrm{~kg} / \mathrm{m}^{3}$ & 1200 \\
\hline ethylene price factor & $c_{l}, \$ / t$ & 1350 \\
\hline Propylene price factor & $c_{2}, \$ / t$ & 1196 \\
\hline naphtha price factor & $c_{0}, \$ / t$ & 500 \\
\hline steam price factor & $c_{H}, \$ / \mathrm{kg}$ & 0.0129 \\
\hline heat price factor & $c_{Q}, \$ / \mathrm{kJ}$ & $1.26 \mathrm{E}-05$ \\
\hline Decoking cost & $D C C,(\$ /$ time $)$ & 66,600 \\
\hline
\end{tabular}

\subsection{Results and discussions}

After performing steady-state optimisation in HYSYS with Hyprotech Sequential Quadratic 
Programming (SQP) solver, the process gas temperature profile obtained was shown in Figure 8. Table 5 summarized other optimisation results and these were compared with the current operating conditions described in [10]. From Table 5, it can be seen that after optimisation, the operating profit was improved obviously. Figure 9 gave the details of main cracking product yields along the reactor tube under the optimal operating conditions.

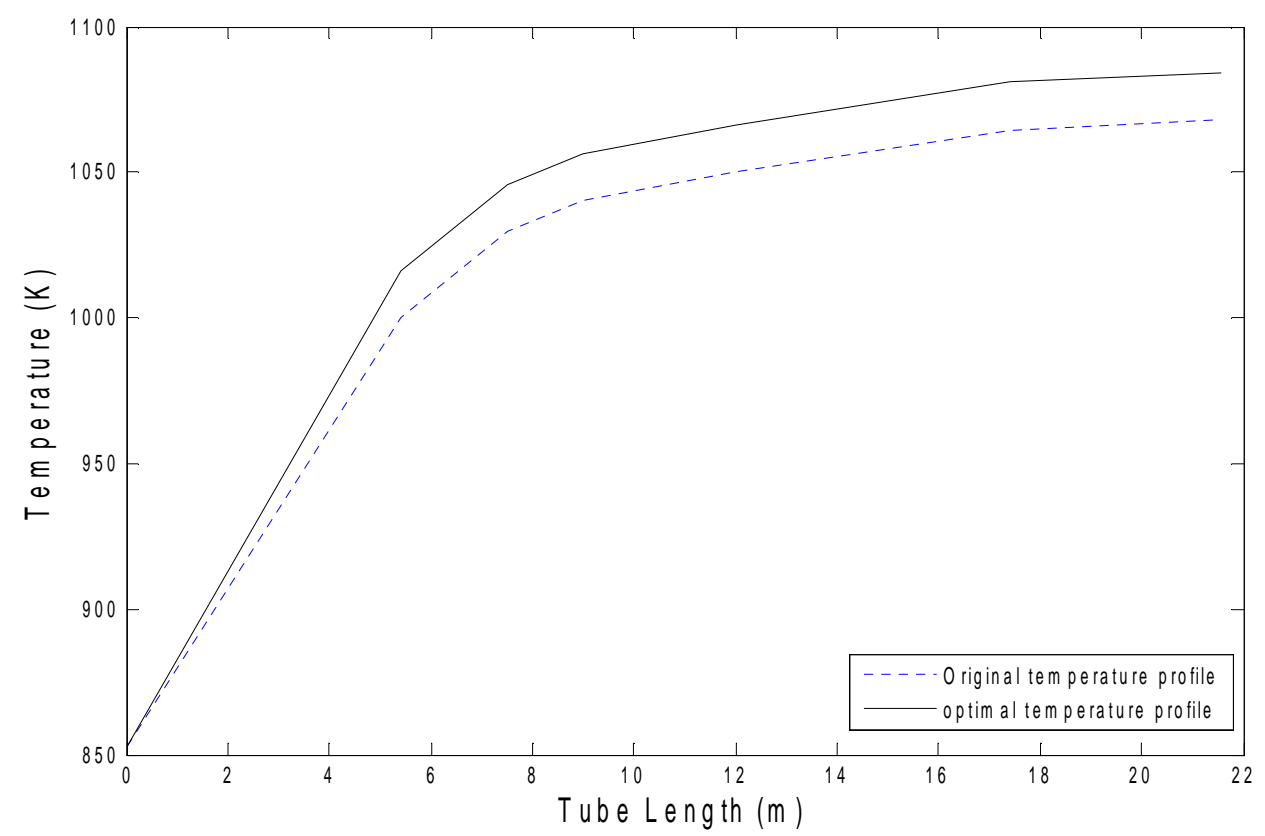

Figure 8 Process gas temperature profile along the reactor tube (obtained from optimisation)

Table 5 Optimisation results

\begin{tabular}{|c|c|c|}
\hline Items & original value & Optimal value \\
\hline Coil out temperature COT $(\mathrm{K})$ & 1068.05 & 1084.15 \\
\hline Steam to naphtha $(\mathrm{kg} / \mathrm{kg})$ ratio & 0.6 & 0.6 \\
\hline $\mathrm{C}_{2} \mathrm{H}_{4}$ yiled $(\mathrm{wt} \%)$ & 25.25 & 29.65 \\
\hline $\mathrm{C}_{3} \mathrm{H}_{6}$ yiled $(\mathrm{wt} \%)$ & 11.44 & 12.83 \\
\hline Objective function value $(\$ /$ year$)$ & $-5.848^{*} 10^{6}$ & $3.03 * 10^{7}$ \\
\hline Radiant heat flux $(\mathrm{kJ} / \mathrm{h})$ & $2.70^{5} 10^{7}$ & 21 \\
\hline $\begin{array}{c}\text { Production time between two } \\
\text { consecutive decokings (days) }\end{array}$ & 41.46 & \\
\hline
\end{tabular}




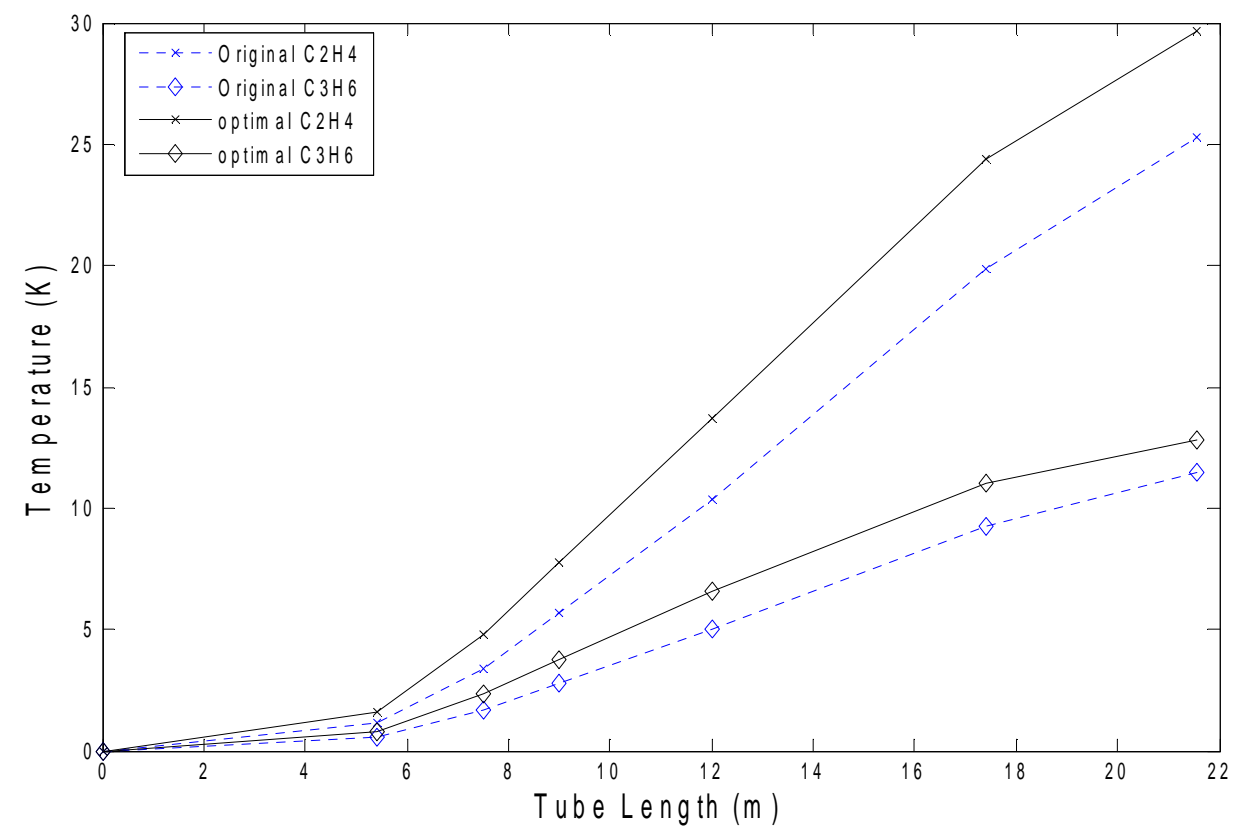

Figure 9 Main cracking product yields along the reactor tube

From Figure 8, the optimal process gas temperature is $1084.15 \mathrm{~K}$ at the outlet of the tubular reactor. Compared with the base case, COT has been increased $16.1 \mathrm{~K}$. In this way, the cracking reaction is much faster and the product yields are higher correspondingly (refer to Table 5 and Figure 9). This contributes higher profits. On the other hand, due to increased temperature over the whole tube length (in the optimal temperature profile), the coking rate becomes higher. Therefore, the expense caused by tubular reactor shutdown for decoking also becomes higher. The optimal steam to naphtha ratio in the feed is still 0.6 (refer to Table 5). So the production time between two consecutive decokings reduced from 41.46 days to 21 days. The operation has been improved from making a loss of $\$ 5.848$ million at the base operating condition to making a profit $\$ 101.6 \mathrm{k}$ at the optimal operating condition.

\section{CONCLUSIONS AND FUTURE WORK}

In this paper, tubular reactors in the industrial thermal cracking furnace presented in [10] were simulated. With the same industrial furnace, the impact of process gas temperature profile and inlet steam to hydrocarbon ratio on the ethylene/propylene product yields and coking rate was studied through various cases. The optimal process temperature profile and the optimal inlet steam to naphtha ratio were found to maximize the operation profit. This study will provide significant guidance to practising process engineers in the ethylene industry.

Future work will be concentrated on (a) to model the coking at the inner wall of the tube varying with time more accurately; (b) to take into account the impact of coking on product yields with time and (c) to consider the coking affecting the production time between two consecutive decokings more accurately. To implement these functions, a more powerful modelling, simulation and optimisation tool such as gPROMS and Aspen Custom Modeler may be required to replace HYSYS since gPROMS and Aspen Custom Modeler have the ability to develop process models according to different scenarios. 


\section{ACKNOWLEDGEMENTS}

Guangying Gao gratefully acknowledges the financial support of the National Scholarship Council, P. R. China for her travel and study at Cranfield University, UK.

\section{References}

[1] Albright, L.F., Crynes, B. L. and Corcoran, W.H. (1983), Pyrolysis Theory and Industrial Practice, Academic Press Inc., New York, USA.

[2] Sundaram, K.M., Shreehan, M.M. and Olszewski, E.F. (2001), Ethylene, in the Kirk-Othmer Encyclopedia of Chemical Technology $\left(5^{\text {th }} \mathrm{Ed}\right)$, John Wiley \& Sons, Inc.

[3] Towfighi, J. and Karimzadeh, R. (1993), Development of a Mechanistic Model for Pyrolysis of Naphtha, $6^{\text {th }}$ Conference of the Asia Pacific Confederation of Chemical Engineering, Vol. 3, Melbourne, Australia.

[4] Wang, Z.Y., Luo, G.J. and Wu, H.Q. (1978), The kinetics model of the naphtha thermal cracking for ethylene (I), Journal of Daqing Petroleum Institute, Vol. 1, No. 2, p1-23.

[5] Wang, Z.Y., Luo, G.J. and Wu, H.Q. (1980), The kinetics model of the naphtha thermal cracking for ethylene (II), Journal of Daqing Petroleum Institute, Vol. 3, No. 1, p8-25.

[6] Kumar, P. and Kunzru, D. (1985a), Modelling of Naphtha Pyrolysis, Ind. Eng. Chem. Process Des. Dev., Vol. 24, p774-782.

[7] Kumar, P. and Kunzru, D. (1985b), Kinetics of coke deposition in naphtha pyrolysis, Canadian Journal of Chemical Engineering, Vol. 63, No. 4, pp598-604.

[8] Shahrokhi, M. and Nejati, A. (2002), Optimal Temperature Control of a Propane Thermal Cracking Reactor. Ind. Eng. Chem. Res., 41, 6572-6578

[9] Masoumi, M.E., Sadrameli, S.M., Towfighi, J. and Niaei. A. (2006), Simulation, optimisation and control of a thermal cracking furnace, Energy, Vol. 31, p516-527.

[10] Lan, X., Gao, J., Xu, C. and Zhang, H. (2007), Numerical Simulation of Transfer and Reaction Processes in Ethylene Furnaces, Trans IChemE, Part A, Chemical Engineering Research and Design, Vol. 85, 1565-1579.

[11] Detemmerman, T. and Froment, G. F. (1998), Three Dimensional Coupled Simulation of Furnaces and Reactor Tubes for the Thermal Cracking of Hydrocarbons, Revue de L'Institut Francais Du Petrole, Vol. 53, No. 2, p181-194.

[12] AspenTech Inc. (2007), Aspen HYSYS® 2006.1 User Guide, Cambridge, MA, USA.

[13] Sundaram, K M., and Froment, G.F. (1977), Modelling of thermal cracking kinetics - II: Cracking of iso-Butane, n-Butane, and Mixtures Ethane-Propane-n-Butane, Chem. Eng. Sci., Vol. 32, p609-617.

[14] ICIS Chemical Business (2006), Chemical Week Price Report, 15 Nov. 2006. 